Original Article

\title{
Overdose of D-serine Induces Movement Disorder and Neuromuscular Changes of Zebrafish Larvae
}

\author{
Xing-Guang Chen ${ }^{1 \#}$, Yun-Hsin Wang ${ }^{2 \#}$, Chi-Chung Wen $^{3}$, and Yau-Hung Chen ${ }^{1 *}$ \\ ${ }^{1}$ Department of Chemistry, Tamkang University, No. 151 Ying-chuan Road, Tamsui, New Taipei City 251, Taiwan \\ ${ }^{2}$ Division of Basic Research, Koo Foundation Sun Yat-Sen Cancer Center, No. 125, Lide Road, Beitou, Taipei, Taiwan \\ ${ }^{3}$ Department of Mathematics, Tamkang University, No. 151, Ying-chuan Road, Tamsui, New Taipei City, Taiwan
}

\begin{abstract}
D-serine is a well-known activator of N-methyl-D-aspartate receptors; however, little is known about the teratogenic effects of D-serine overdose during early embryonic development. Here, we used zebrafish as a model to test toxicity and teratogenicity, since they have transparent eggs, making the organogenesis of zebrafish embryos easier to be observed. After D-serine injection (100-1000 ppm), the most evident defective phenotypes were bent trunk phenotypes, including malformed somite boundary, twisted body axis and shorter body length. As the injection dosages increased, the rates of embryos with bent trunk phenotypes decreased $(0 \%$ for $0 \mathrm{ppm}$, $\mathrm{n}=573 ; 59.9 \sim 84.3 \%$ for $100-1000 \mathrm{ppm}$ of $\mathrm{D}$-serine, $\mathrm{n}=383-451$ ). In addition, $\mathrm{D}$-serine-injected embryos exhibited significantly reduced the frequencies of spontaneous in-chorion contraction ( 21.7 for $0 \mathrm{ppm}$ vs. $18.3-0.9$ for 100-1000 ppm D-serine, $\mathrm{n}=30$ ) in comparison with mock-treated controls $(0 \mathrm{ppm})$. Subtle changes are easily observed by staining with specific monoclonal antibodies F59, Znp1, Zn5 and $\alpha$-bungarotoxin to detect morphological changes in muscle fibers, primary motor axons, secondary motor axon projections and neuromuscular junctions, respectively. Our data show that overdose of D-serine leads to misalignment of muscle fibers and motor neuron defects, especially secondary motor neuron axonal growth defects. (DOI: 10.1293/tox.2013-0032; J Toxicol Pathol 2014; 27: 19-24)
\end{abstract}

Key words: D-serine, developmental toxicity, NMDA receptor

\section{Introduction}

The standard amino acids are of the L-form, but their enantiomers, D-amino acids, are found in some proteins, such as peptidoglycan cell walls of bacteria ${ }^{1,2}$. It has been reported that $\mathrm{D}$-amino acids accumulated in different tissues, which might represent different physiological conditions. For example, accumulation of D-aspartate and D-hydroxyproline in dentin, tooth enamel and the crystalline lens can be used as aging index ${ }^{3,4}$. Also, a large amount of D-serine accumulation was found in the frontal brain, cerebellum, cortex, hippocampus and microglia ${ }^{5-7}$. These findings indicate that the distributions of $\mathrm{D}$-amino acids are diverse and may have different physiological roles.

D-serine is highly associated with neurodegenerative diseases such as schizophrenia and amyotrophic lateral sclerosis (ALS) $)^{8-13}$. Importantly, it was reported that D-serine could act as a potent activator of N-methyl-D-aspartate (NMDA)-type glutamate receptors ${ }^{14-16}$, indicating that D-

Received: 6 June 2013, Accepted: 4 September 2013

*Corresponding author: Y-H Chen (e-mail: yauhung@mail.tku.edu. tw)

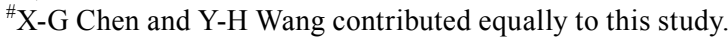

(C)2014 The Japanese Society of Toxicologic Pathology

This is an open-access article distributed under the terms of the Creative Commons Attribution Non-Commercial No Derivatives (by-ncnd) License $<$ http://creativecommons.org/licenses/by-nc-nd/3.0/> .

Published online in J-stage: 6 January 2014 serine is an important neurotransmitter. In mammalians and zebrafish, blockage of NMDA receptors induces some neurological defects, such as seizures and impairment of learning and memory. This means that the biological roles of D-serine might be conserved between zebrafish and mammalians ${ }^{17-21}$. In this regard, D-serine-induced toxicity is worthy of study.

In rats, $\mathrm{D}$-serine exposure resulted in changes in a number of pathways that may be associated with neuronal dysfunction $^{22}$. In addition, administration of D-serine induced oxidative stress and resulted in renal tubular necrosis and hyperaminoaciduria ${ }^{23-25}$. These observations indicated that an excess of D-serine caused severe adverse effects such as neurotoxicity and nephrotoxicity in adult animals. However, the developmental toxicities of D-serine have not been fully clarified. Thus, development of an alternative model to study D-serine-induced developmental toxicities is essential.

Zebrafish are a good model for toxicological experiments because they produce a large number of transparent embryos and have well-characterized developmental stages. To develop a zebrafish model for studying D-serine-induced developmental toxicities, we generated a series of time- and dose-dependent D-serine exposure experiments. By staining with specific monoclonal antibodies, subtle changes in neuronal axon formation and myofibril alignment can be easily observed. This strategy is efficient for studying D-serine-induced developmental toxicities. 


\section{Materials and Methods}

\section{Fish care, embryo collection and D-serine adminis- tration}

Mature zebrafish (AB strain) were raised at the zebrafish facility of the Life Sciences Development Center, Tamkang University. Embryos were produced using standard procedures ${ }^{26}$ and were staged according to standard criteria (hours post fertilization, hpf $)^{27}$ or by days post fertilization (dpf). D-serine (Sigma) was dissolved in sterile distilled water to the desired concentrations $(0,100,500,1000 \mathrm{ppm})$, and was microinjected with a Nanoliter 2000 (World Precision Instruments, Sarasota, FL, USA) into the cytoplasm of one-cell stage embryos ( $2.3 \mathrm{nl} / \mathrm{embryo})$. After microinjection, embryos were cultivated at $28.5^{\circ} \mathrm{C}$, and survival rates were determined at 27 and $48 \mathrm{hpf}$.

\section{Spontaneous embryonic contractions}

The spontaneous in-chorion contraction of zebrafish embryos was analyzed as previously described ${ }^{28,29}$. Briefly, zebrafish embryos at $24 \mathrm{hpf}$ without or with injection of different concentrations $(100,500$ and $1000 \mathrm{ppm})$ of D-serine were collected and recorded. Spontaneous in-chorion contractions were defined based on the angle of the tail displacement relative to the body axis. Embryos with tail movements from one side to the other at any angles were classified as having in-chorion contraction.

\section{Antibody labeling, acetylcholine receptor clustering and microscopy}

F59 monoclonal antibody (Hybridoma Bank; 1:10), Znp1 (Hybridoma Bank; 1:200) and Zn5 (Hybridoma Bank; 1:200) staining and acetylcholine receptor clustering were performed as previously described, except for the fact that 27- and 48-hpf zebrafish embryos were collected ${ }^{30-33}$. After labeling, all embryos were observed at specific stages under a microscope (DM 2500, Leica) equipped with Nomarski differential interference contrast optics and a fluorescent module having a GFP or DsRed filter cube (Kramer Scientific). Photographs of embryos at specific stages were taken with a CCD (DFC490, Leica).

\section{Statistical analysis}

All analyses in this study were carried out using the MATLAB software (version 7.7 R2008b). The two-way ANOVA (analysis of variance) was applied to test the effects of factors (exposure time, dosage level) on the mean of the outcome variable (survival rate or malformation rate). The P-value for each factor, reported by two-way ANOVA, was associated with the null hypothesis that samples at all levels of the factor are drawn from the same population. The Tukey-Kramer HSD (honestly significant difference) test was further used to compare the population marginal means for one factor, adjusted by removing the effect of other factors. The one-way ANOVA and Tukey-Kramer HSD test were employed to compare the average number of in-chorion contractions between dose groups. A significance level of 0.05 was used in all statistic analyses, and a familywise error rate of 0.05 was controlled for in the Tukey-Kramer HSD test.

\section{Results}

Visible and defective phenotypes of embryos after injection of D-serine and survival rates analysis

In order to study the exposure time and dosage effects of D-serine on zebrafish larvae, we injected zebrafish embryos with different dosages of D-serine (100, 500 and 1000 $\mathrm{ppm}$ ) and calculated their survival rates at $27 \mathrm{hpf}$ or $48 \mathrm{hpf}$. As shown in Table 1 and Table 2, around $55.7-67.9 \%$ of the embryos injected with D-serine were alive at $27 \mathrm{hpf}$, and the survival rates decreased to $15.6-48.6 \%$ at $48 \mathrm{hpf}$. The twoway ANOVA revealed that the P-values for exposure time and dose effects on survival rate were 0.0754 and 0.0417 , respectively. The former indicated the survival rates decreased as the time of exposure increased but not to a significant degree. The latter indicated a significant difference in survival rates between dosage groups. The Tukey-Kramer HSD test was thus used to pairwise compare the marginal mean survival rates for dosage level groups, adjusted by exposure time effect. The adjusted mean survival rates for the $0,100,500$ and $1000 \mathrm{ppm}$ dosage groups were $93.54 \%$, $58.26 \%, 51.97 \%$ and $35.63 \%$ with a common standard error of $7.49 \%$, and the difference in survival rate between the $1000 \mathrm{ppm}$ D-serine-injected group and mock-treated group $(0 \mathrm{ppm})$ was significant. Consequently, D-serine injection led to a reduction in the survival rates of zebrafish embryos.

We further examined the phenotypic defects caused by D-serine. Compared with mock-treated embryos, D-serineinjected embryos (100-1000 ppm, 27 hpf) displayed some defective phenotypes (bent trunk phenotypes), such as a malformed somite boundary, twisted body axis and shorter body length (Fig. 1A vs. 1B, 1C, 1D).

Similar results were also observed at $48 \mathrm{hpf}$ (Fig. 1E vs. $1 \mathrm{~F}, 1 \mathrm{G}, 1 \mathrm{H})$. The $\mathrm{D}$-serine-induced malformation rates were $59.9 \%-84.3 \%$ and $61.6-68.6 \%$ at 27 and $48 \mathrm{hpf}$, respectively (Tables 1 and 2). Statistically, the two-way ANOVA indicated that the D-serine effect on the malformation rate was significant $(\mathrm{P}$-value $=0.0027)$. Furthermore, the Tukey-Kramer HSD test revealed that the mean malformed rates, adjusted by exposure time effect, for the $0,100,500$ and $1000 \mathrm{ppm}$ dosage groups were $0 \%, 60.90 \%, 66.00 \%$, and $76.46 \%$ with a common standard error of $4.07 \%$ and identified that each of the D-serine injected groups (100, 500, and $1000 \mathrm{ppm})$ differed significantly from the control group $(0 \mathrm{ppm})$ at a familywise error rate of 0.05 , but no significant difference existed among the doses.

\section{Spontaneous in-chorion contraction was reduced in $D$-serine-injected embryos}

We also noted that D-serine-injected embryos seemed to have less mobility at early larval stages. Thus, spontaneous in-chorion contractions in 27-hpf embryos were examined. The times of in-chorion contraction for each group 
Table 1. Morphological Phenotypes of 27-hpf Zebrafish Embryos Derived from Fertilized Eggs Injected with Different Concentrations of D-serine

\begin{tabular}{cccccc}
\hline $\begin{array}{c}\text { Injection } \\
\text { dose }(\mathrm{ppm})\end{array}$ & $\begin{array}{c}\text { Injected } \\
\text { embryos }\end{array}$ & $\begin{array}{c}\text { Survival } \\
\text { embryos }\end{array}$ & $\begin{array}{c}\text { Survival } \\
\text { rates }^{\#}\end{array}$ & $\begin{array}{c}\text { Malformed } \\
\text { embryos }\end{array}$ & $\begin{array}{c}\text { Malformed } \\
\text { rates }^{\S}\end{array}$ \\
\hline 0 & 600 & 573 & $95.5 \%$ & 0 & $0 \%$ \\
100 & 664 & 451 & $67.9 \%$ & 270 & $59.9 \%$ \\
500 & 653 & 394 & $60.3 \%$ & 276 & $70.0 \%$ \\
1000 & 688 & 383 & $55.7 \%$ & 323 & $84.3 \%$ \\
\hline
\end{tabular}

\# (Surviving embryos/injected embryos $\times 100 \%$ ); ${ }^{\S}$ (Malformed embryos/surviving embryos $\times 100 \%$ ).

Table 2. Morphological Phenotypes of 48-hpf Zebrafish Embryos Derived from Fertilized Eggs Injected with Different Concentrations of D-serine

\begin{tabular}{cccccc}
\hline $\begin{array}{c}\text { Injection } \\
\text { dose }(\mathrm{ppm})\end{array}$ & $\begin{array}{c}\text { Injected } \\
\text { embryos }\end{array}$ & $\begin{array}{c}\text { Survival em- } \\
\text { bryos }\end{array}$ & Survival rates $^{\#}$ & $\begin{array}{c}\text { Malformed } \\
\text { embryos }\end{array}$ & $\begin{array}{c}\text { Malformed } \\
\text { rates }^{\S}\end{array}$ \\
\hline 0 & 700 & 641 & $91.6 \%$ & 0 & $0 \%$ \\
100 & 638 & 310 & $48.6 \%$ & 192 & $61.9 \%$ \\
500 & 844 & 368 & $43.6 \%$ & 228 & $62.0 \%$ \\
1000 & 776 & 121 & $15.6 \%$ & 83 & $68.6 \%$ \\
\hline
\end{tabular}

\# (Surviving embryos/injected embryos $\times 100 \%$ ); ${ }^{\S}$ (Malformed embryos/surviving embryos $\times 100 \%$ ).

were recorded for $3 \mathrm{~min}$. As shown in Fig. 2, the average number ( \pm standard error) of in-chorion contractions in the mock-treated control ( 0 ppm of D-serine) embryos was 21.7 \pm 0.69 ( 3 min per embryo; $n=30$ ). On the other hand, the average numbers of in-chorion contractions in the embryos injected with 100,500 and $1000 \mathrm{ppm}$ of D-serine were 18.3 $\pm 0.97,12.7 \pm 0.83$ and $0.9 \pm 0.23(\mathrm{n}=30)$, respectively. The one way ANOVA test revealed a highly significant difference $(\mathrm{P}$-value $<0.0001)$ in the average number of in-chorion contractions between dose groups, and the Tukey-Kramer HSD test identified all pairwise differences as significant at a familywise error rate of 0.05 . This demonstrated that D-serine treatment reduced significantly the motilities of zebrafish embryos.

\section{Injection of D-serine results in disorganized muscle fibers alignments}

To further investigate the molecular mechanisms resulting in the reduced spontaneous in-chorion contraction of D-serine-injected embryos, the monoclonal antibody F59 was used to visualize the alignments of muscle fibers in mock-treated control and D-serine-injected zebrafish embryos. In the mock-treated control embryos (27 hpf), muscle fibers aligned well in the $\mathrm{V}$-shaped somites (Fig. 3A). In contrast, muscle fibers aligned disorderly after injection of 100-1000 ppm of D-serine (Fig. 3B-3D). Similar results were observed but were more severe at $48 \mathrm{hpf}$ (Fig. 3E vs. $3 \mathrm{~F}-3 \mathrm{H})$. These observations strongly indicate that injection of D-serine results in dose- and time-dependent defects of disorganized muscle fiber alignment.

\section{D-serine causes motor axons and neuromuscular junctions defects}

To address whether the projections of motor axons and the formation of neuromuscular junctions were affected by injection of D-serine, monoclonal antibody Znpl and $\alpha$-bungarotoxin labeling were carried out. The antibody Znp1 labeled the axonal bundles of primary motoneurons (pre-synapses) and revealed the common axonal path as well as the projections into ventral and dorsal somitic muscle blocks in mock-treated control embryos at $27 \mathrm{hpf}$ (Fig. $4 \mathrm{~A})$. In addition, $\alpha$-bungarotoxin bound to acetylcholine receptors (AchRs; post-synapses) (Fig. 4B) and revealed clusters of AchRs. The merged signals suggested that axonal projections correlated well with the clusters of AchRs (Figs. $4 \mathrm{C}-4 \mathrm{D}$, yellow signals), indicating that the motor axons innerved to the muscle fiber functionally. Interestingly, we found that only $8.1 \%$ (5/61, numbers of defective embryos/ total number of D-serine-injected embryos) of D-serine-injected zebrafish embryos displayed defective primary motoneuronal pre-synapses and clusters of AchRs (Fig. 4D-4F). These observations suggest that overdose of D-serine seems to have little effects on primary motor neuron projection.

Axons of secondary motor neurons enter the common path set out by the primary neurons and complete migration as one nerve. When the development of primary motor neurons is impaired, the outgrowth of secondary motor axons is disrupted as well ${ }^{34}$. We labeled secondary motor neurons with monoclonal $\mathrm{Zn} 5$, and the results revealed that secondary motor neurons completed their axonal migration along the common path and reached the trajectory point at $48 \mathrm{hpf}$ (Fig. 5A). However, secondary motor neuron axonal growth was impaired by injection of $100 \mathrm{ppm}$ of D-serine $(30.7 \%$, 65/212; Fig. 5B). At higher concentrations (500 and 1000 ppm), secondary motor neuron axonal growth was nearly abandoned (Figs. 5C-5D). Taken together, we suggest that overdose of D-serine can cause motor neuron defects, especially for secondary motor neuron axonal growth. 


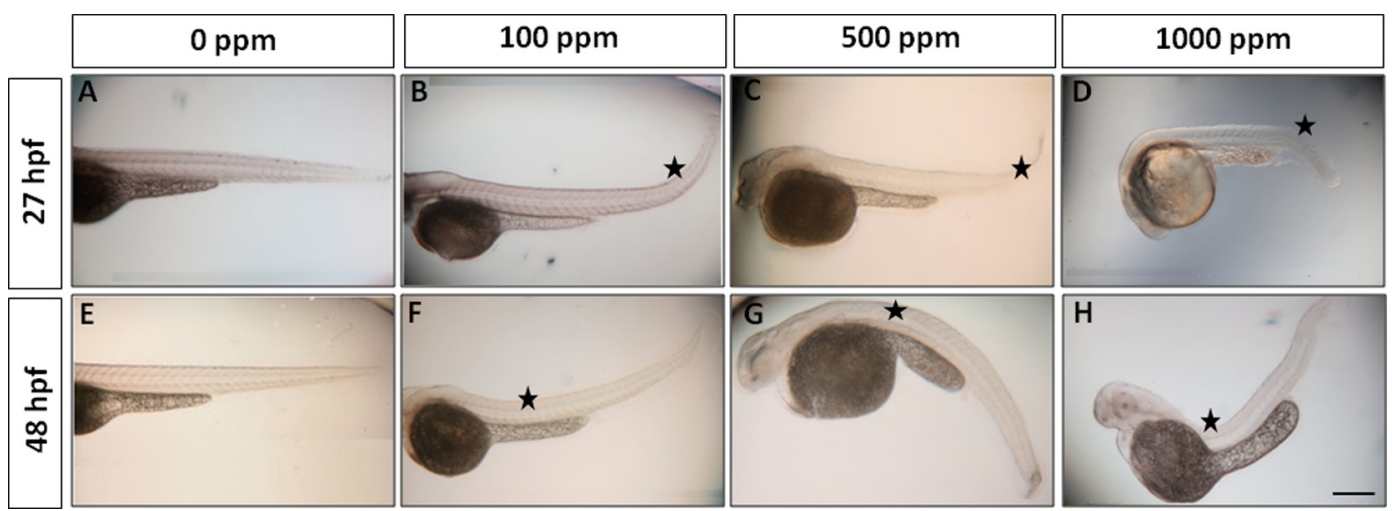

Fig. 1.

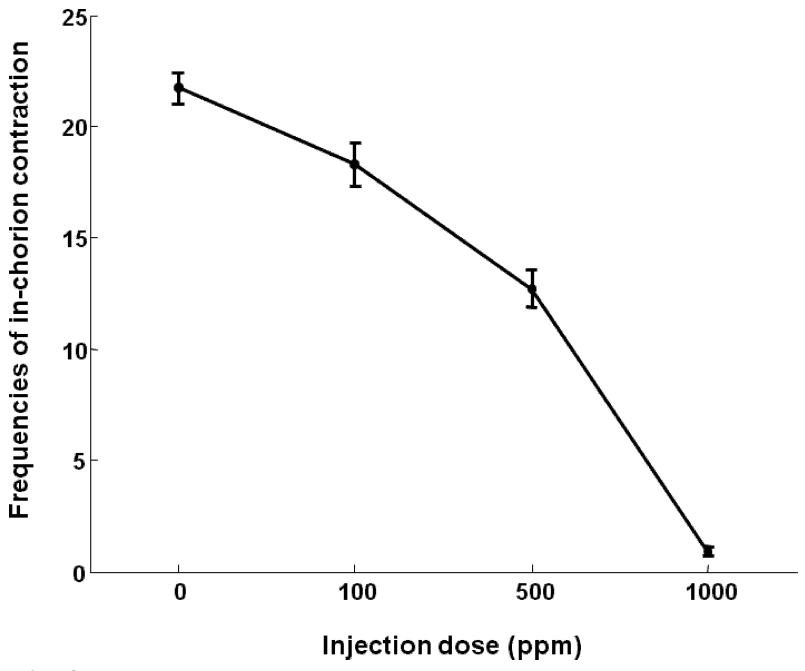

Fig. 2.
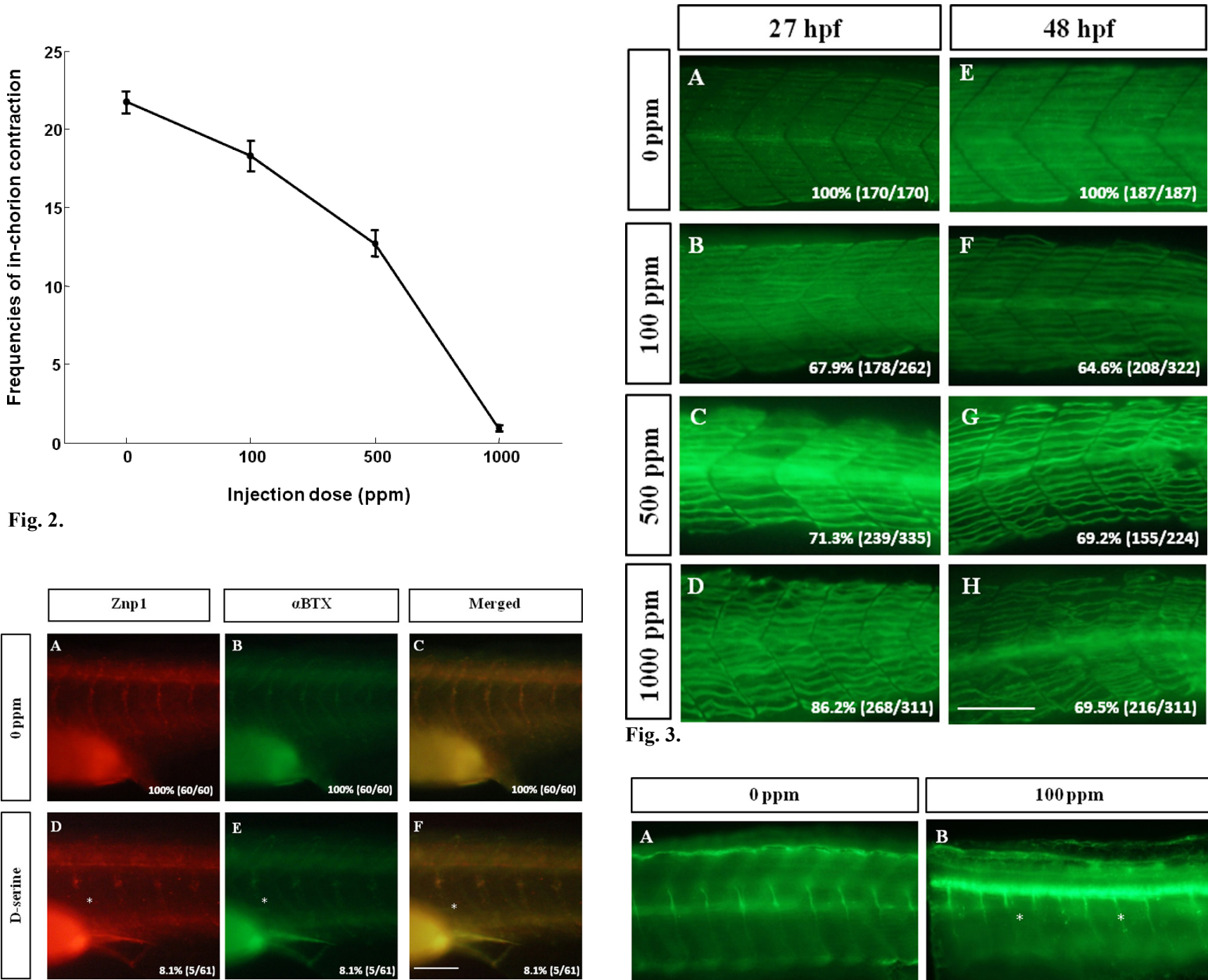

Fig. 4.
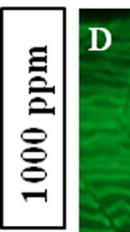

Fig. 3.
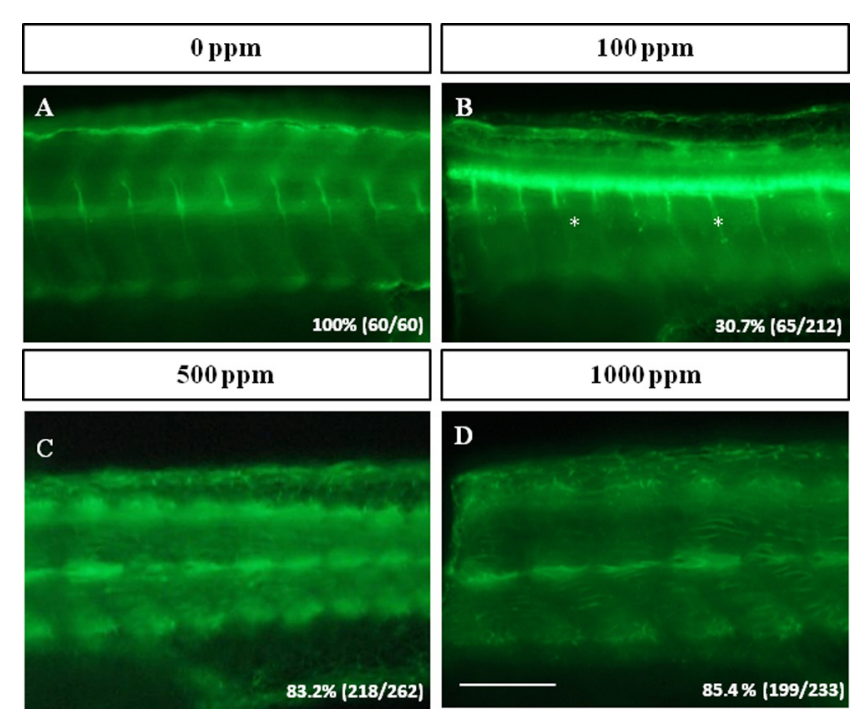

\section{Discussion}

D-serine is a coagonist of NMDA receptors and plays a significant role in neuronal activity, including learning, memory and cell-death signaling ${ }^{35,36}$. As might be expected, increased levels of D-serine are associated with excitotoxicity of NMDA receptors ${ }^{32}$. In adult rats, injection of 50-200 $\mathrm{mg} / \mathrm{kg}$ D-serine induced oxidative stress, which was thought
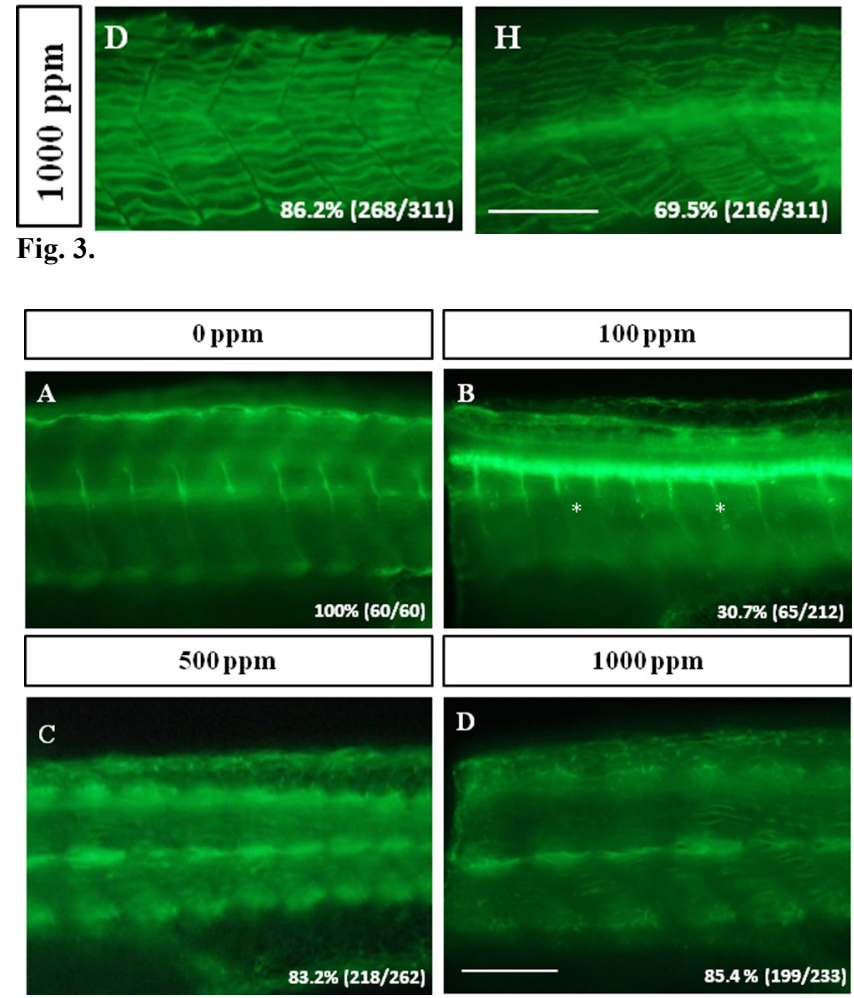

Fig. 5. 
Fig. 1. Injection of D-serine leads to curved-body embryos. Zebrafish embryos were injected with water (A, E) or water containing 100 , 500 or $1000 \mathrm{ppm}$ of D-serine (B-D, F-H), and were recorded at 27 and $48 \mathrm{hpf}$. A star indicates the bent trunk region. Scale bar: $250 \mu \mathrm{m}$.

Fig. 2. Effects of D-serine on spontaneous in-chorion contractions. Frequencies of spontaneous in-chorion contractions of zebrafish embryos after injection of $0,100,500$, and $1000 \mathrm{ppm}$ of D-serine were measured. The times of in-chorion contraction for each group were recorded for $3 \mathrm{~min}$. The X- and Y-axes represent concentrations of D-serine and frequencies of in-chorion contraction, respectively.

Fig. 3. F59 monoclonal antibody-staining of the zebrafish embryos after injection of 0, 100, 500, and 1000 ppm of D-serine. (A-D) 27 hpf, (E-H) $48 \mathrm{hpf}$. Data are presented as percentages: numbers of shown embryos/total numbers of D-serine-injected embryos surviving at the check point (27 or 48 hpf). Scale bar: $100 \mu \mathrm{m}$.

Fig. 4. Znp1 monoclonal antibody-staining (A, D) and $\alpha$-bungarotoxin labeling (B, E) of the 27-hpf zebrafish embryos after injection with 100 ppm of D-serine. Merged pictures: $(\mathrm{C})$, panels A and B, $(\mathrm{F})$ panels D and E. The yellow signals in panel C indicate that the Znpl-positive cells are also $\alpha$-bungarotoxin positive. Data are presented as percentages: numbers of shown embryos/total numbers of D-serine-injected embryos surviving at $27 \mathrm{hpf}$. A star indicates the defective region. Scale bar: $100 \mu \mathrm{m}$.

Fig. 5. Zn5 monoclonal antibody-staining of the 48-hpf zebrafish embryos after injection with different doses of D-serine. (A) 0 ppm, (B) 100 ppm, (C) 500 ppm and (D) 1000 ppm. Data are presented as percentages: numbers of shown embryos/total numbers of D-serine-injected embryos surviving at $48 \mathrm{hpf}$. A star indicates the defective region. Scale bar: $100 \mu \mathrm{m}$.

to be neurotoxic to the brain ${ }^{37}$. Our data showed that zebrafish embryos injected with 100,500 and 1000 ppm of D-serine displayed a significant decrease in in-chorion contraction (Fig. 2) and few defects in primary motor neuron axonal growth but did not display severe impairment of secondary motor neuron projection (Figs. 4 and 5). Based on published information, we speculate that the D-serine-induced neural defects in zebrafish might be due to impairment of NMDA receptor function and that the injection concentrations described in this study are appropriate for exploration of Dserine-induced neurotoxicities.

In addition to neuronal malformation, we also found that embryos injected with D-serine displayed severe muscle defects, especially myofibril misalignment (Fig. 3). Here, we propose two possible causes contributing to D-serineinduced muscle defects. One possibility is that such muscle malformation in D-serine-injected zebrafish embryos might result from D-serine affecting the NMDA receptors of the pre-synapse and disturbing the release of neurotransmitters from the axon terminals. Previous studies have shown that knockdown of neuronal activity led to impairment of muscle development ${ }^{28,38}$. In this regard, D-serine-induced muscle defects might be the consequences of excitotoxicity of NMDA receptors. In other words, muscle defects are an indirect defect caused by D-serine-induced neuronal toxicity. The other possibility is that D-serine affects the muscletype NMDA receptor or even an unknown muscle-specific receptor, and disturbs muscle development. In mouse $\mathrm{C} 2 \mathrm{C} 12$ myoblasts, it has been demonstrated that NMDA receptors were expressed in myoblasts during muscle differentiation, and played a role in myoblasts fusion ${ }^{39}$. In rats, NMDA receptors were found to be present at the neuromuscular junctions (NMJ) of the diaphragm ${ }^{40,41}$. These observations suggested that NMDA receptors have direct effects on muscle development. Thus, whether or not NMDA receptors are present at the myoblasts of developing zebrafish embryos merits further study.

Acknowledgment: This project was supported by the National Science Council, Republic of China, under grant numbers NSC 100-2313-B-032-001 and NSC 101-2313-B032-001-MY3.

\section{References}

1. Tymoczko JL, Berg JM, and Stryer L. Biochemistry. Second printing. W.H. Freeman and Company, New York. 2010.

2. van Heijenoort J. Formation of the glycan chains in the synthesis of bacterial peptidoglycan. Glycobiology. 11: 25R36R. 2001. [Medline] [CrossRef]

3. Hashimoto A, Nishikawa T, Oka T, and Takahashi K. Endogenous D-serine in rat brain: N-methyl-D-aspartate receptor-related distribution and aging. J Neurochem. 60: 783-786. 1993. [Medline] [CrossRef]

4. Fujii N. D-amino acid in elder tissues. Biol Pharm Bull. 28: 1585-1589. 2005. [Medline] [CrossRef]

5. Hashimoto A, Nishikawa T, Hayashi T, Fujii N, Harada K, Oka T, and Takahashi K. The presence of free D-serine in rat brain. FEBS Lett. 296: 33-36. 1992. [Medline] [CrossRef]

6. Williams SM, Diaz CM, Macnab LT, Sullivan RK, and Pow DV. Immunocytochemical analysis of D-serine distribution in the mammalian brain reveals novel anatomical compartmentalizations in glia and neurons. Glia. 53: 401-411. 2006. [Medline] [CrossRef]

7. Kakegawa W, Miyoshi Y, Hamase K, Matsuda S, Matsuda K, Kohda K, Emi K, Motohashi J, Konno R, Zaitsu K, and Yuzaki M. D-Serine regulates cerebellar LTD and motor coordination through the $\mathrm{d} 2$ glutamate receptor. Nat Neurosci. 14: 603-611. 2011. [Medline] [CrossRef]

8. Tsai G, Yang P, Chung L, Lange N, and Coyle JT. D-serine added to antipsychotics for the treatment of schizophrenia. Biol Psychiatry. 44: 1081-1089. 1998. [Medline] [CrossRef]

9. Hashimoto K, Fukushima T, Shimizu E, Komatsu N, Watanabe $H$, Shinoda N, Nakazato M, Kumakiri C, Okada S, Hasegawa H, Imai K, and Iyo M. Decreased serum levels of D-serine in patients with schizophrenia. Arch Gen Psychiatry. 60: 572-576. 2003. [Medline] [CrossRef]

10. Bendikov I, Nadri C, Amar S, Panizzutti R, De Miranda J, Wolosker H, and Agam GA. CSF and postmortem brain study of D-serine metabolic parameters in schizophrenia. Schizophr Res. 90: 41-51. 2007. [Medline] [CrossRef]

11. Nishikawa T. Analysis of free D-serine in mammals and its biological relevance. J Chromatogr B Analyt Technol Biomed Life Sci. 879: 3169-3183. 2011. [Medline] [CrossRef]

12. Sasabe J, Chiba T, Yamada M, Okamoto K, Nishimoto I, 
Matsuoka M, and Aiso S. D-Serine is a key determinant of glutamate toxicity in amyotrophic lateral sclerosis. EMBO J. 26: 4149-4159. 2007. [Medline] [CrossRef]

13. Sasabe J, Miyoshi Y, Suzuki M, Mita M, Konno R, Matsuoka M, Hamase $\mathrm{K}$, and Aiso S. D-Amino acid oxidase controls motoneuron degeneration through D-serine. Proc Natl Acad Sci USA. 109: 627-632. 2012. [Medline] [CrossRef]

14. Schell MJ, Molliver ME, and Snyder SH. D-serine, an endogenous synaptic modulator: localization to astrocytes and glutamate-stimulated release. Proc Natl Acad Sci USA. 92: 3948-3952. 1995. [Medline] [CrossRef]

15. Mothet JP, Parent AT, Wolosker H, Brady RO Jr, Linden DJ, Ferris CD, Rogawski MA, and Snyder SH. D-Serine is an endogenous ligand for the glycine site of the N-methyl-Daspartate receptor. Proc Natl Acad Sci USA. 97: 4926-4931. 2000. [Medline] [CrossRef]

16. Wolosker H, Dumin E, Balan L, and Foltyn VN. D-amino acids in the brain: D-serine in neurotransmission and neurodegeneration. FEBS J. 275: 3514-3526. 2008. [Medline] [CrossRef]

17. Hunt RF, Hortopan GA, Gillespie A, and Baraban SC. A novel zebrafish model of hyperthermia-induced seizures reveals a role for TRPV4 channels and NMDA-type glutamate receptors. Exp Neurol. 237: 199-206. 2012. [Medline] [CrossRef]

18. Sison M, and Gerlai R. Associative learning performance is impaired in zebrafish (Danio rerio) by the NMDA-R antagonist MK-801. Neurobiol Learn Mem. 96: 230-237. 2011. [Medline] [CrossRef]

19. Chen J, Patel R, Friedman TC, and Jones KS. The behavoiral and pharmacological actions of NMDA receptor antagonism are conserved in zebrafish larvae. Int J Comp Psychol. 23: 82-90. 2010. [Medline]

20. McDearmid JR, and Drapeau P. Rhythmic motor activity evoked by NMDA in the spinal zebrafish larva. J Neurophysiol. 95: 401-417. 2006. [Medline] [CrossRef]

21. Cox JA, Kucenas S, and Voigt MM. Molecular characterization and embryonic expression of the family of N-methyl-D-aspartate receptor subunit genes in the zebrafish. Dev Dyn. 234: 756-766. 2005. [Medline] [CrossRef]

22. Davidson ME, Kerepesi LA, Soto A, and Chan VT. DSerine exposure resulted in gene expression changes implicated in neurodegenerative disorders and neuronal dysfunction in male Fischer 344 rats. Arch Toxicol. 83: 747-762. 2009. [Medline] [CrossRef]

23. Wise EM Jr, and Elmyn D. Hyperaminoaciduria in rats following D-serine administration. Proc Soc Exp Biol Med. 121: 982-986. 1966. [Medline] [CrossRef]

24. Kaltenbach JP, Ganote CE, and Carone FA. Renal tubular necrosisinduced by compounds structurally related to D-serine. Exp Mol Pathol. 30: 209-214. 1979. [Medline] [CrossRef]

25. Soto A, DelRaso NJ, Schlager JJ, and Chan VT. D-Serine exposure resulted in gene expression changes indicative of activation of fibrogenic pathways and down-regulation of energy metabolism and oxidative stress response. Toxicology. 243: 177-192. 2008. [Medline] [CrossRef]

26. Westerfield M. The Zebrafish Book, 3rd ed. University of Oregon Press, Eugene. 1995.
27. Kimmel CB, Ballard WW, Kimmel SR, Ullmann B, and Schilling TF. Stages of embryonic development in the zebrafish. Dev Dyn. 203: 253-310. 1995. [Medline] [CrossRef]

28. Chen YH, Huang FL, Cheng YC, Wu CJ, Yang CN, and Tsay HJ. Knockdown of zebrafish Nav1.6 sodium channel impairs embryonic locomotor activities. J Biomed Sci. 15: 69-78. 2008. [Medline] [CrossRef]

29. Chen YH, Chang CY, Wang YH, Wen CC, Chen YC, Hu $\mathrm{SC}$, Yu DS, and Chen YH. Embryonic exposure to diclofenac disturbs actin organization and leads to myofibril misalignment. Birth Defects Res B: Dev Reprod Toxicol. 92: 139-147. 2011. [Medline] [CrossRef]

30. Tsay HJ, Wang YH, Chen WL, Huang MY, and Chen YH. Treatment with sodium benzoate leads to malformation of zebrafish larvae. Neurotoxicol Teratol. 29: 562-569. 2007. [Medline] [CrossRef]

31. Wang YH, Li CK, Lee GH, Tsay HJ, Tsai HJ, and Chen YH. Inactivation of zebrafish mrf4 leads to myofibril misalignment and motor axon growth disorganization. Dev Dyn. 237: 1043-1050. 2008. [Medline] [CrossRef]

32. Lee GH, Chang MY, Hsu CH, and Chen YH. Essential roles of basic helix-loop-helix transcription factors, Capsulin and Musculin, during craniofacial myogenesis of zebrafish. Cell Mol Life Sci. 68: 4065-4078. 2011. [Medline] [CrossRef]

33. Tsai IT, Chen YH, Chen YH, and Wang YH. Amikacininduced fin reduction is mediated by autophagy. J Toxicol Pathol. 26: 79-82. 2013. [Medline] [CrossRef]

34. Tessier-Lavigne $\mathrm{M}$, and Goodman CS. The molecular biology of axon guidance. Science. 274: 1123-1133. 1996. [Medline] [CrossRef]

35. Pollegioni L, and Sacchi S. Metabolism of neuromodulator D-serine. Cell Mol Life Sci. 67: 2387-2404. 2010. [Medline] [CrossRef]

36. Armagan G, Kanit L, and Yalcin A. D-serine treatment induces oxidative stress in rat brain. Drug Chem Toxicol. 34: 129-138. 2011. [Medline] [CrossRef]

37. Armagan G, Kanit L, and Yalcin A. Effects of non-steroidal antiinflammatory drugs on D-serine-induced oxidative stress in vitro. Drug Chem Toxicol. 35: 393-398. 2012. [Medline] [CrossRef]

38. McWhorter ML, Monani UR, Burghes AHM, and Beattie CE. Knockdown of the survival motor neuron (Smn) protein in zebrafish causes defects in motor axon outgrowth and pathfinding. J Cell Biol. 162: 919-931. 2003. [Medline] [CrossRef]

39. Lee KH, Park JY, and Kim K. NMDA receptor-mediated calcium influx plays an essential role in myoblast fusion. FEBS Lett. 578: 47-52. 2004. [Medline] [CrossRef]

40. Berger UV, Carter RE, and Coyle JT. The immunocytochemical localization of n-acetylaspartyl glutamate, its hydrolysing enzyme NAALADase, and the NMDAR-1 receptor at a vertebrate neuromuscular junction. Neuroscience. 64: 847-850. 1995. [Medline] [CrossRef]

41. Grozdanovic Z, and Gossrau R. Co-localization of nitric oxide synthase I (NOS I) and NMDA receptor subunit 1 (NMDAR-1) at the neuromuscular junction in rat and mouse skeletal muscle. Cell Tissue Res. 291: 57-63. 1998. [Medline] [CrossRef] 